\title{
Spectral signature of brown rust and orange rust in sugarcane
}

\author{
Firma espectral de la roya parda y la roya naranja en la caña de azúcar
}

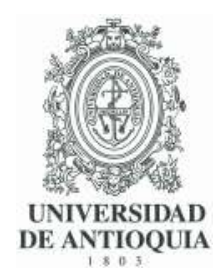

\section{Jorge Luís Soca-Muñoz (1) 1 , Eniel Rodríguez-Machado ${ }^{2}$, Osmany Aday-Díaz $\mathbb{1}^{3}{ }^{3}$, Luis Hernández-Santana ${ }^{2}$, Rubén Orozco Morales (1) $^{*}$}

${ }^{1}$ Centro de Estudios Termoenergéticos, Universidad Carlos Rafael Rodríguez. Cuatro Caminos, Carretera Rodas, km 3 1/2, Cienfuegos. C.P. 55100. Cienfuegos, Cuba.

${ }^{2}$ Grupo de Automatización, Robótica y Percepción (GARP), Universidad Central Marta Abreu de Las Villas, Cr. Camajuaní, km. 5.5. C.P. 54830. Santa Clara, Villa Clara, Cuba.

${ }^{3}$ Estación Territorial de Investigaciones de la Caña de Azúcar (ETICA Centro Villa Clara), Instituto de Investigaciones de la Caña de Azúcar. INICA Autopista Nacional, Km 246, Ranchuelo, Villa Clara. C.P. 53100. La Habana, Cuba.

\section{CITE THIS ARTICLE AS:}

J. L. Soca, E. Rodríguez, 0 .

Aday, L. Hernández and R.

Orozco. "Spectral signature of brown rust and orange rust in sugarcane", Revista Facultad de Ingeniería Universidad de Antioquia, no. 96, pp. 9-20, Jul-Sep 2020. [Online]. Available: https:

//www.doi.org/10.17533/ udea.redin. 20191042

\section{ARTICLE INFO:}

Received: July 27, 2018

Accepted: October 01, 2019

Available online: October 01 , 2019

\section{KEYWORDS:}

Remote sensing; sugar cane; pests; vegetation; agriculture

Teledetección; caña de azúcar; plagas; vegetación; agricultura
ABSTRACT: Precision agriculture, making use of the spatial and temporal variability of cultivable land, allows farmers to refine fertilization, control field irrigation, estimate planting productivity, and detect pests and disease in crops. To that end, this paper identifies the spectral reflectance signature of brown rust (Puccinia melanocephala) and orange rust (Puccinia kuehnii), which contaminate sugar cane leaves (Saccharum spp.). By means of spectrometry, the mean values and standard deviations of the spectral reflectance signature are obtained for five levels of contamination of the leaves in each type of rust, observing the greatest differences between healthy and diseased leaves in the red $(R)$ and near infrared $(N I R)$ bands. With the results obtained, a multispectral camera was used to obtain images of the leaves and calculate the Normalized Difference Vegetation Index (NDVI). The results identified the presence of both plagues by differentiating healthy from contaminated leaves through the index value with an average difference of $11.9 \%$ for brown rust and $9.9 \%$ for orange rust.

RESUMEN: La agricultura de precisión, haciendo uso de la variabilidad espacial y temporal de las tierras cultivables, permite a los agricultores refinar la fertilización, controlar la irrigación de los campos, estimar la productividad de la siembra, así como detectar plagas y enfermedad en los cultivos. Con ese fin, en este trabajo se identifica la firma de reflectancia espectral de la roya parda (Puccinia melanocephala) y la roya naranja (Puccinia kuehnii), que contaminan hojas de caña de azúcar (Saccharum spp.). Mediante espectrometría se obtienen los valores medios y las desviaciones estándares de la firma de reflectancia espectral para cinco niveles de contaminación de las hojas en cada tipo de roya, observándose las mayores diferencias entre hojas sanas y enfermas en las bandas roja $(R)$ e infrarroja cercana $(N I R)$. Con los resultados obtenidos, se utilizó una cámara fotográfica multiespectral para obtener imágenes de las hojas y calcular mediante estas el índice de vegetación de diferencia normalizada (NDVI: Normalized Difference Vegetation Index). Los resultados permitieron identificar la presencia de ambas plagas diferenciando hojas sanas de contaminadas mediante el valor del índice con una diferencia promedio del $11.9 \%$ para roya parda y del $9.9 \%$ para roya naranja.

\section{Introduction}

Sugar cane is one of the main sources of production of sugar and other by-products, with the sugar industry being one of the largest industries in many places, and a source

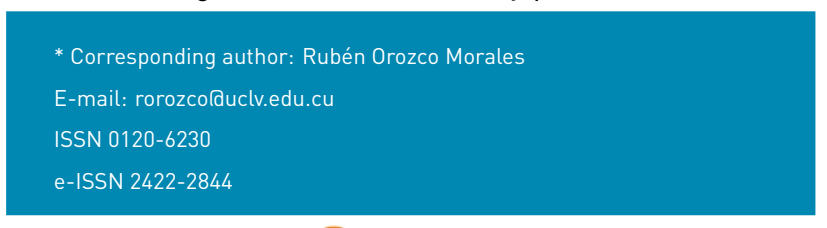

of employment for hundreds of thousands of people in the tropical regions of the world, while cane sugar is an ingredient of many foods. The diseases caused by rust are considered one of the most destructive for agricultural crops. In particular, the species of the genus Puccinia cause the most severe damage to plants, due to the large effects they can cause on the yield of susceptible cultivars $[1,2]$. 
The brown rust disease of sugarcane, widely distributed in almost all the sugarcane areas of the world, is caused by the phytopathogenic fungus Puccinia melanocephala $\mathrm{H}$. Sydow and P. Sydow, and is considered to be one of the most important diseases due to its affectation to the crop. Losses range from $10 \%$ to more than $50 \%$ in susceptible cultivars [3-7]. The orange rust of sugar cane (Puccinia kuehnii (W. Krüger) E. J. Butler) is a parasite that infects only species and hybrids of the genus Saccharum. The orange rust is one of the most important at present, since it causes the decrease in the agricultural yield of the plant, with the consequent economic losses for the producers [8-12].

Like the rust of other crops, the brown and orange rust of sugar cane are characterized by causing foliar lesions that, when evolving, break the epidermis of the leaf, giving the surface of the leaf a rough appearance. These lesions reduce the chlorophyll content of infected leaves, the efficacy of carbon fixation, stomata conductance and rate of photosynthesis [13]. In conditions of high severity, pustules and lesions collapse and necrotic the leaves [14]. This necrosis in the leaves cause the loss of water from the plant, leads to water stress and causes the reduction of the yield of the stems $[15,16]$. Unlike brown rust, the causal agent of orange rust produces orange lesions on the leaves (pustules), very small. The most frequent dimensions of pustules of $P$. kuehnii reach the length between 0.75 and $3.0 \mathrm{~mm}$ and between 0.24 and $0.61 \mathrm{~mm}$ in width, which tend to cluster in the form of patches [17].

The traditional method of detecting both types of rust is by visual inspection according to the conspicuous symptoms described above. However, this procedure is time consumer and an intensive work, increasing the complexity of its application with the extension of the areas to be scrutinized, and needing the intervention of experts highly prepared for this task. Therefore, an efficient and effective method of early detection of the presence of rust is necessary. This should be able to cover large areas of crop in a short time, and also give the possibility of providing graphical evidence, by means of images, of the exact regions that are contaminated, as well as the degree of contamination of each region in particular.

An alternative to achieve this is the use of aerial images obtained in various bands of the electromagnetic spectrum. These images allow what is known as hyperspectral and multispectral analysis, which is now widely used in agriculture. These are based on collecting the reflectance of each element of a scene at different wavelengths, $\rho(\lambda)$, taken with special receptors able to differentiate the various wavelengths, both visible light and other outside the visible range, as is the infrared region of the electromagnetic spectrum [18]. Different properties of the components of a scene are manifested through the spectral composition of the wavelengths that each component of the scene emits. For each wavelength or range of these, a reflectance factor indicates how much of the incident radiation is reflected. Thus, $\rho(\lambda)=100 \%$ means that all incident radiation is reflected, whereas $\rho(\lambda)=0 \%$ means that all incident radiation is absorbed [19]. The graph of $\rho(\lambda)$ is called the spectral reflectance curve, this curve is characteristic of each material, so it is also called spectral reflectance signature, being a unique correspondence between a material and its reflectance spectrum [20-23].

Currently, characterizing scenes through their spectral reflectance signature using spectrometers has become a very useful alternative to identify the presence of objects that are difficult to identify using other traditional methods, such as texture analysis, color segmentation, etc. The spectral reflectance signature of vegetation varies for various reasons. Chlorophyll in healthy leaves strongly absorbs radiation at the wavelengths of red and blue, but reflects that of green [24]. Beyond the visible zone, the plants show a strong increase in reflectance in what is called the near infrared plateau [25]. The scientific literature specialized in obtaining spectral reflectance signatures collects several works for the study of the presence of pests from images in which their spectral content is characterized by different frequency bands [26-28]. These analyzes have the characteristic of being specific for each type of pest and for the local atmospheric conditions, which influence the spectral composition of the illumination and, therefore, of the obtained images.

On the other hand, multispectral images, unlike the curves provided by the spectral reflectance signatures obtained with spectrometers, are monochromatic images taken with photographic cameras for a reduced group of different wavelengths by means of optical filters. The wavelengths used by multispectral cameras are generally a subset of those contained in a spectral reflectance signature. Using multispectral images we can obtain vegetation indices (VI), quantitative measurements obtained for each pixel of the image from a combination of the reflectance values at various spectral bands in a form designed to produce a simple amount that indicates the vigor of the vegetation contained in each pixel of the image. These indices allow us to estimate and evaluate the state of health of the vegetation, based on the measurement of the radiation that the plants emit or reflect [29]. Therefore, by knowing the reflectance of vegetation at different wavelengths, it is possible to calculate vegetation indices, create maps and georeferenced images, which can be used for pest detection.

One of the first applications of multispectral imaging 
was to detect the spread of the corn plague in the American Midwest [30]. In [31] a study is made with the objective of collecting and analyzing the spectral reflectance signatures of sugarcane leaves infected by white leaf disease and thus determine the level of infection of the plant. More recently, in [32] spectral evaluations were carried out in Brazil in cultivars of sugarcane susceptible to orange rust. These authors estimated the bidirectional reflectance factor (BRF) from radiometric measurements. In addition, vegetation indices were calculated, such as the standardized red edge difference vegetation index $\left(N D V I_{705}\right)$, the modified red edge normalized difference vegetation index $\left(m \mathrm{NDVI}_{705}\right)$, as well as an index to measure the effectiveness of the use of radiation in photosynthesis, the photochemical reflectance index $(P R /)$. The results showed, in the spectral curve of leaves of healthy sugar cane, higher BRF than those infected by the orange rust in the spectral region of the green, and lower values of BRF in leaves infected by the fungus in the near infrared region. The determination of vegetation indices was important to determine the differences in spectral behavior in infected and healthy sugarcane leaves, especially with PRI. However, since the classic work of Apan et al.[33], published in 2004, in which hyperspectral imaging data from the Hyperion satellite were used to detect orange rust disease in sugar cane fields in Australia, there is very little research dedicated to identifying the spectral reflectance signature of rust diseases in sugar cane.

This paper presents a study of spectral reflectance signatures that show sugarcane leaves contaminated with brown rust ( $P$. melanocephala) and orange rust ( $P$. kuehnii), obtained by spectrometry. From this study, we used a multispectral camera to obtain the normalized difference vegetation index (NDVI). The NDVI obtained in each case allowed differentiating between healthy leaves and those contaminated with rust, mainly for brown rust. The results identified the presence of both pests by differentiating healthy from contaminated leaves through the index value with an average difference of $11.87 \%$ for brown rust and $9.94 \%$ for orange rust.

\section{Materials and methods}

\subsection{Methodology}

As mentioned above, this study begins with the identification of the spectral reflectance signature of brown rust ( $P$. melanocephala) and orange rust ( $P$. kuehnii), which contaminate sugarcane crops (Saccharum spp.). Our methodology focuses on the identifying of spectral bands capable of differentiating between healthy and contaminated leaves. These bands were finally used to obtain multispectral images, which allows the calculation of a vegetation index capable of distinguishing the difference between the presence and absence of rust. To do this, we follow the steps below:

1) Selection of cultivars.

2) Preparation of culture samples.

3) Use of the spectrometer to obtain spectral signatures.

4) Use of multispectral camera to obtain images in spectral bands of interest.

5) Calculating the vegetation index.

6) Analysis of results.

The steps of this methodology are summarized in Figure 1 and described in the following subsections.

\subsection{Preparation of culture samples}

The samples of brown rust were collected in an experiment considered as proof of resistance to this disease of cultivars under study. This experiment was planted in September 2016 in the experimental block of the Estación Territorial de Investigaciones de la Caña de Azúcar Centro Villa Clara (ETICA Centro Villa Clara), province of Villa Clara, Cuba. This station belongs to the Instituto de Investigaciones de la Caña de Azúcar (INICA). The collection of the leaves was done close to 11:00 am in the month of March 2017, having an age of six months. The samples of orange rust were collected in an experiment for the evaluation of resistance of commercial cultivars to orange rust and monitoring of the evolution of this disease. Samples of this experiment were planted and harvested equally in ETICA Centro Villa Clara, in the same dates of the brown rust. For the study, samples of leaves infected with the brown rust of cultivar B4362 (susceptible to $P$. melanocephalal and of leaves infected with the orange rust of cultivar C01-227 (susceptible to $P$. kuehnii) were collected.

For the selection of samples of infected leaves, in each case a leaf diagnosis was first adopted, leaves +3 (third leaf with visible dewlap) were collected, using the scale of five degrees of attack severity lestimating the percentage of area foliar affected by pustules), according to [34], where: grade 1 is applied when the affected leaf area $(A L A)$ reaches up to $5 \%(A L A \leq 5 \%)$, grade $215 \%<$ $A L A \leq 15 \%)$, grade $3(15 \%<A L A \leq 25 \%)$, grade $4(25 \%<$ $A L A \leq 50 \%)$ and grade $5(50 \%<A L A)$. Subsequently, the presence of the causative agent was confirmed through an optical microscope, taking into account the characteristics and morphological differences of the uredospores of both rusts described by [35]. Cultivars with grade 1 are considered resistant to brown rust and orange rust, and grade 5 are considered highly susceptible [36]. Five leaves 


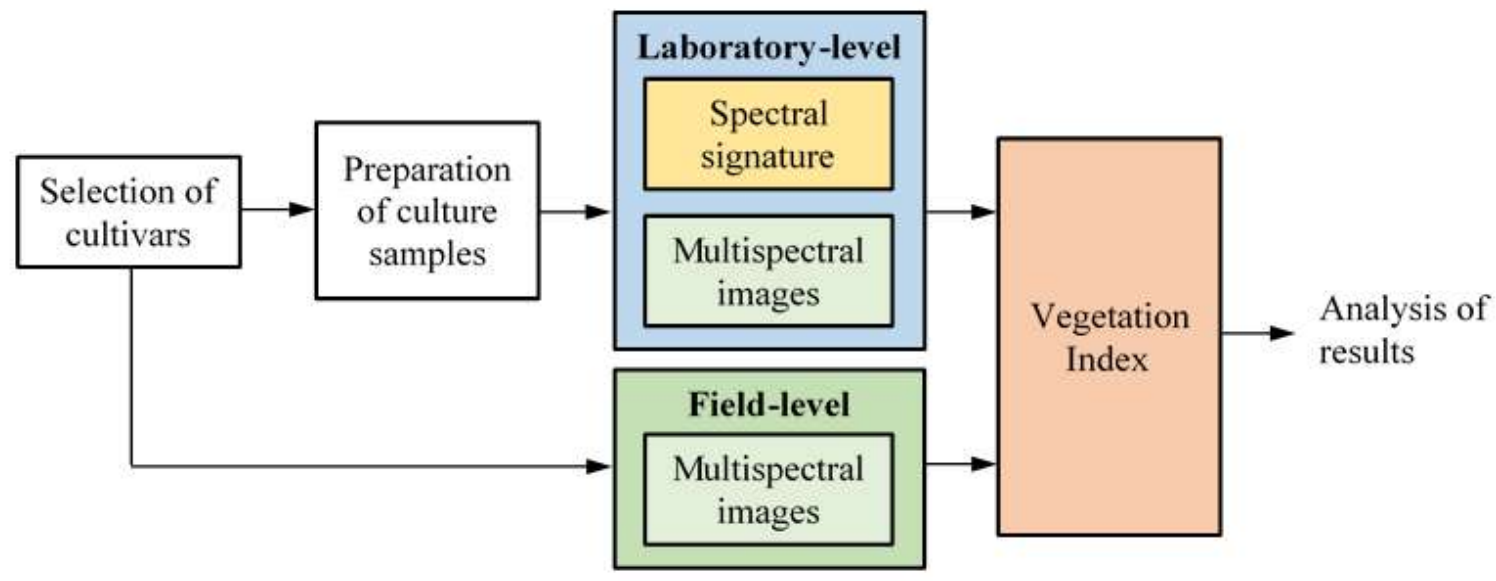

Figure 1 Experimental methodology

of cultivar B4362 were collected, one healthy (not infected by $P$. melanocephalal and four infected by brown rust with ALA grade between 1 and 4. In the same way, five leaves of the cultivar C01-227 (susceptible to $P$. kuehnii) were collected: one healthy (not infected by $P$. kuehnii) and four infected by orange rust with ALA grade between 1 and 4 .

\subsection{Use of the spectrometer to obtain spectral signatures}

To obtain the spectral reflectance signature, the Corona Plus Remote spectrometer (Figure 2), marketed by the German firm Carl Zeiss, was used. This is a laboratory equipment that has a measuring head that is connected to the central unit using fiber optics and this unit in turn connects to a PC for the analysis of the data and visualization of the results via the Ethernet interface. Its reflectance measurement range is from $398 \mathrm{~nm}$ to $1,702 \mathrm{~nm}$ in 422 bands, with a spectral resolution lower than $10 \mathrm{~nm}$, sensing a circular area of sample with approximately $2.5 \mathrm{~mm}$ radius, equivalent to $20 \mathrm{~mm}^{2}$. The curves were obtained reading in points along each leave with separations between 20 and $30 \mathrm{~mm}$ approximately, without taking into account that the reading is made on a contaminated area or not.

The data obtained by the spectrometer were processed by the Aspect Plus software, version 1.76 (C) (https://www.zeiss.com/spectroscopy/products/ software/aspect-plus.html). This is a modular and flexible spectral analysis software package that works under MS Windows. Through Aspect Plus, spectral measurements and processing can be performed for the Zeiss MCS 5xx and Corona spectrometers.

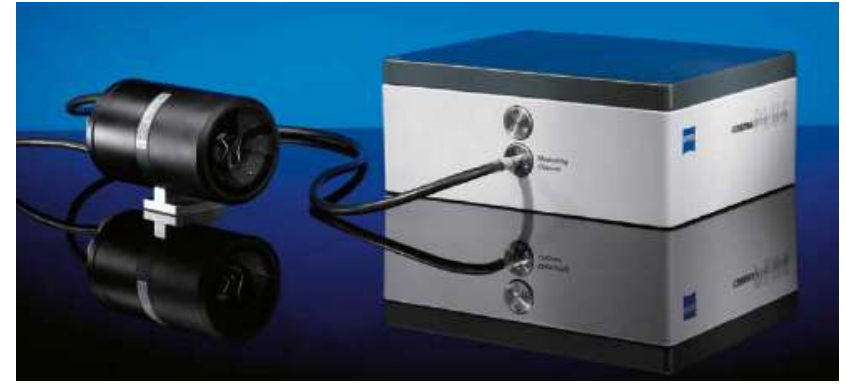

Figure 2 Spectrometer Corona Plus Remote (https://www.zeiss.com/spectroscopy/products/ spectrometer-systems/corona-plus-remote.html)

\subsection{Multispectral images production}

To validate the practical application of the analysis of the obtained spectral reflectance signatures, images obtained with a multispectral camera were used. The multispectral images were obtained using the Parrot Sequoia camera (https://www.parrot.com/ business-solutions-us/parrot-professional/ parrot-sequoial. This camera contains five independent sensors that operate simultaneously to obtain their respective images in the different spectral bands, a sunshine intensity sensor to adjust the cameras to the existing lighting conditions, a GPS module, an inertial measurement unit that registers the orientation of the cameras, as well as a magnetometer that acts as a compass and indicates the direction in the flight. Designed for agriculture with excellent precision, it can be adapted to all types of drones. The data provided by all these components are integrated as metadata in captured images.

The five cameras obtain respectively a panchromatic image $(R G B)$ of $16 \mathrm{Mpx}(4,608 \times 3,456), 24$ bits per pixel (8 bpp for each channel of color), with a pixel of $1.34 \mu \mathrm{m}$, 


\section{P. melanocephala (brown rust)}

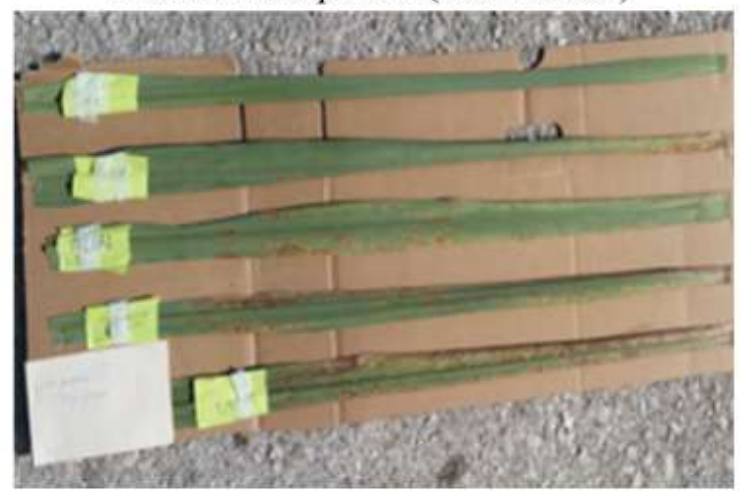

P. kuehnii (orange rust)

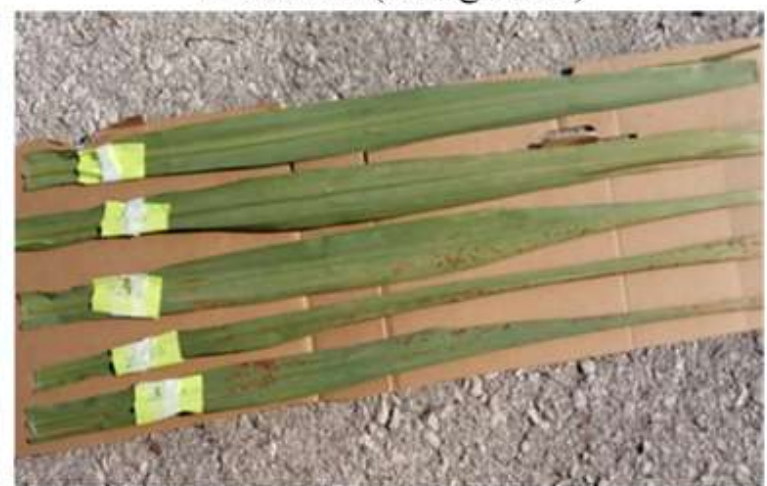

Figure 3 Examples of leaves used contaminated with brown rust and orange rust

focal length of $4.88 \mathrm{~mm}$, and are saved in JPG format, as well as four monochromatic images in: 1) range of green $(G)$ at $550 \mathrm{~nm}$ with $40 \mathrm{~nm}$ bandwidth (BW), 2) range of red $(R)$ at $660 \mathrm{~nm}$ with $40 \mathrm{~nm} \mathrm{BW}, 3)$ range of red edge $(R E)$ at $735 \mathrm{~nm}$ with $10 \mathrm{~nm} \mathrm{BW}$, and 4) range of near infrared (NIR) at $790 \mathrm{~nm}$ with $40 \mathrm{~nm}$ BW. The monochromatic images are 1.2 Mpx (1,288x960), 16 bits per pixel $(65,536$ gray levels), with $3.75 \mu \mathrm{m}$ pixel, $3.98 \mathrm{~mm}$ focal length, and are saved in TIF format.

Using the Parrot Sequoia multispectral camera with sun lighting in the morning of a clear day, images of the sugarcane leaf samples were taken. The distance between the camera and the leaves was approximately $1.5 \mathrm{~m}$, which gives a resolution at ground level, or ground sample distance $(G S D)$, of $1.4 \mathrm{~mm}$ per pixel. The $G S D$ determines the spatial resolution of the images. This is defined as those fine details that can be captured by the images or what portion of the ground can cover a pixel of the image. The smaller the GSD in a digital image, the smaller the details that can be captured and the greater the spatial resolution. According to [37], this distance can be calculated using Equation 1,

$$
G S D=\frac{H P_{s}}{f}
$$

where $H$ is the height at which the image was taken, $P_{s}$ is the distance between pixels in the camera sensor (pitch), and $f$ the focal length of the camera lens. From the $G S D$ used, it is achieved that the spots of contamination with rust in the leaves can be covered by several pixels in the image, making clearly visible the pixels of the image that correspond to the affected regions when calculating the indexes. This analysis must be taken into account for images taken at distances of several tens of meters, in which the distance covered by a pixel of the image is greater than the size of the spot on the contaminated region of the leaf. Figure 3 shows an example of some of the leaves used contaminated with orange rust and brown rust.

A second validation of the analysis of the obtained spectral reflectance signatures was performed at field level. For this purpose, multispectral images were taken with the Parrot Sequoia camera, inserted in an unmanned aerial vehicle that flew at a height of $80 \mathrm{~m}$ over the parcels from which the sugar cane leaves were extracted with each type of rust.

\subsection{Calculating the vegetation index}

The normalized difference vegetation index (NDVI) is used to extract vegetation abundance from remote sensing data by isolating the dramatic increase in reflectance over the visible wavelengths from red $\rho(R)$ to the reflectance from near infrared $\rho(N I R)$, and normalizes it by dividing by the total reflectance of each pixel at those wavelengths using Equation 2.

$$
N D V I=\frac{\rho(N I R)-\rho(R)}{\rho(N I R)+\rho(R)}
$$

In this experiment, the $N D V I$ is obtained by taking multispectral images in the red $(R)$ and near infrared $(N / R)$ bands. Thus, each pixel of the image calculated using Equation 2 indicates the value of the NDVI at its location on the leaf as shown in sections 3.2 and 3.3.

In theory, the value of this index ranges between -1 and 1 . However, in practice the measurements generally range between -0.1 and $0.8[38,39]$. Clouds, water, snow and ice give negative values of NDVI. Naked soils and other background materials produce NDVI values between -0.1 and 0.1 . The highest NDVI values occur when the amount of green vegetation in the observed area increases, ranging from 0.2 to 0.8 . Healthy plants have a high NDVI value due to their high infrared reflectance and relatively low red light reflectance. Phenology and vigor are the main factors 

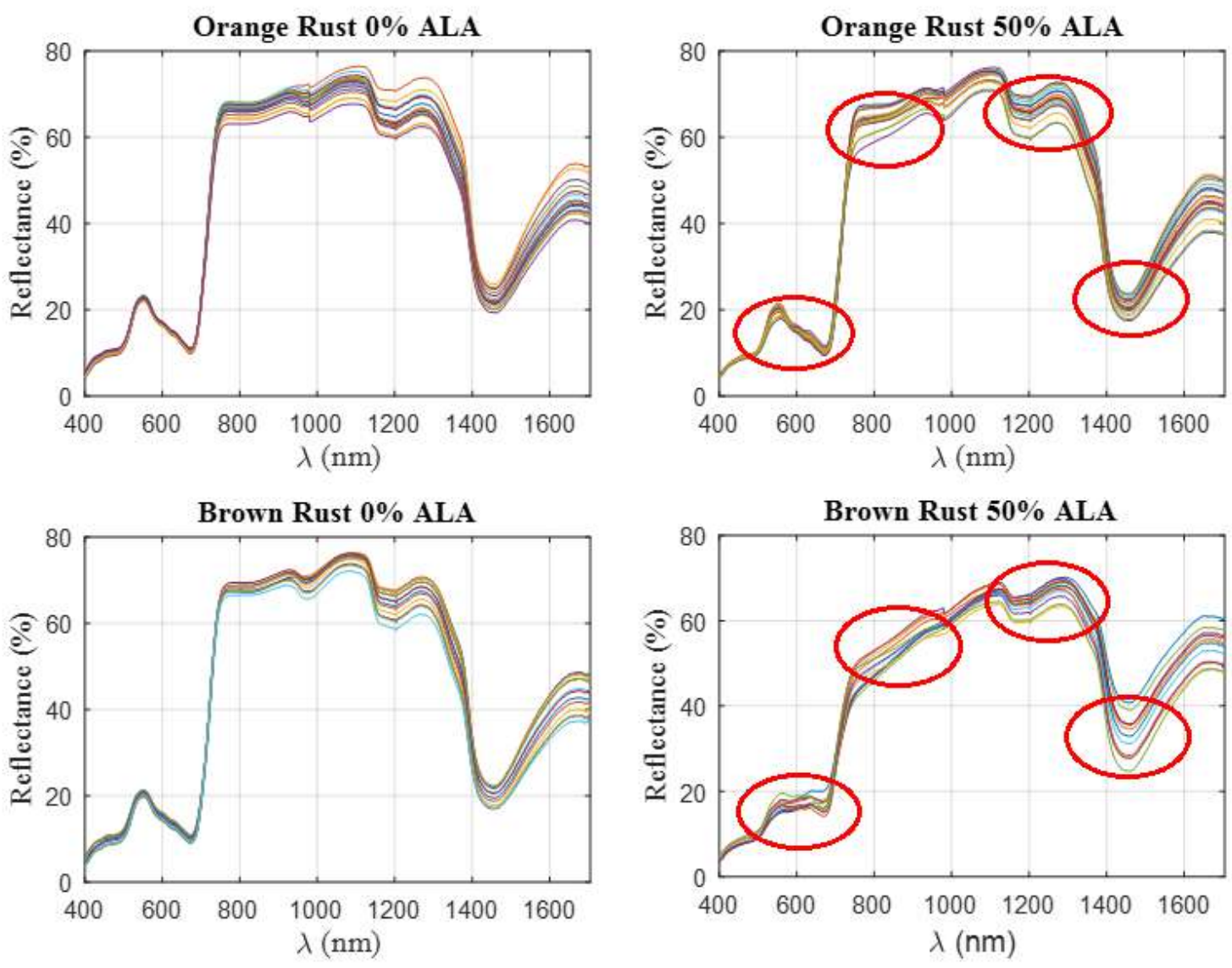

Figure 4 Spectral reflectance signatures of healthy leaves $(0 \%$ of $A L A)$, and contaminated leaves $(50 \%$ of $A L A)$ with orange rust (upper row) and brown rust (lower row)

that affect the NDVI, so it is possible to estimate the state of the health of the plant in general, the photosynthetic activity, and the possible deficit of nutrients, as well as to study the spatial and temporal tendencies in the dynamics of vegetation, productivity and distribution. In [40] the NDVI is used to identify areas of sugarcane and evaluate their health condition from images of the IRS LISS-II satellite, which makes it possible to calculate the area of the land surface covered by the crop and which portion is diseased. The authors of [41] used the NDVI, among other indices, to demonstrate the influence of water deficit in the low fruit production in apple trees. The work in [42] measures sugarcane yield potential across a large number of genotypes using canopy reflectance measurements, such as NDVI. Recently, Johansen et al. [43] investigated the use of high-spatial resolution satellite image data and geographic object-based image analysis, based on NDVI, to map putative sugarcane grub damage. In [44] also focused on the task of classifying sugarcane, taking as input NDVI time series extracted from remotely sensed images. In addition, the authors of [45] evaluated the potential of the NDVI to monitoring changes in sugarcane yield imposed by different straw removal rates. Finally,
Zheng et al. [46] explored the potential of the Sentinel-2 satellite to discriminate between the severities of yellow rust infection in winter wheat using some vegetation indices, such as NDVI. However, research relating NDVI to brown rust and orange rust in sugarcane has been poorly evaluated in the literature.

\section{Results}

\subsection{Analysis of spectral signatures}

Using the Corona Plus Remote spectrometer and the samples of sugarcane leaves contaminated with brown rust and orange rust, we obtained the spectral reflectance curves that are shown in Figure 4. For healthy leaves, the low spectral reflectance in the portion of the blue $(450 \mathrm{~nm})$ and red $(670 \mathrm{~nm})$ bands is observed in Figure 4, due to the strong absorption by the leaf pigments (mainly chlorophyll). On the contrary, a peak of reflectance in the green portion $(550 \mathrm{~nm})$ is manifested. In the NIR region (700-1,300 $\mathrm{nm}$ ), the high reflectance of the leaves can be seen, a characteristic in which cellular 

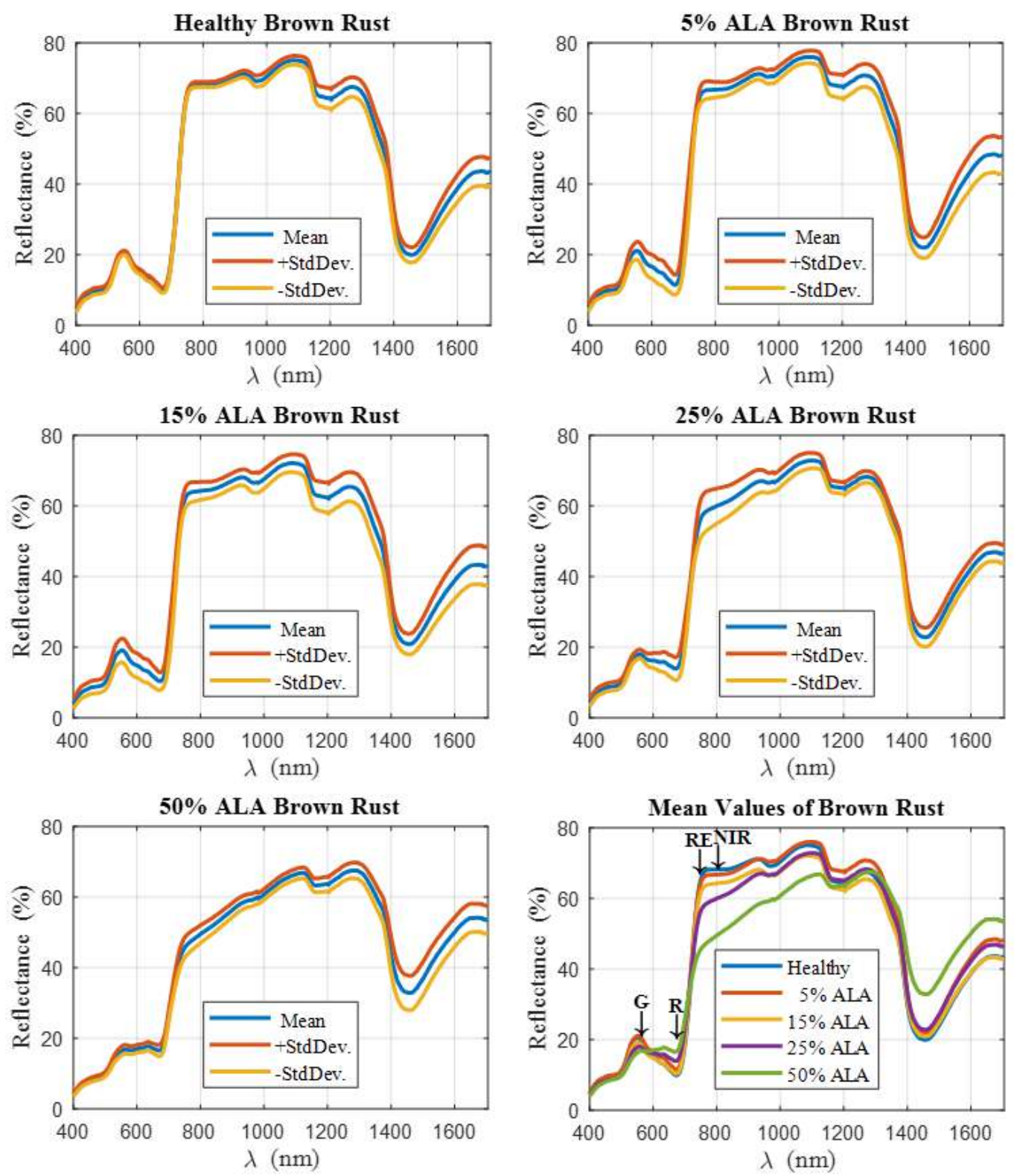

Figure 5 Mean values and standard deviation of spectral signatures of healthy leaf and contaminated with brown rust in ALA grades of 1 to 4 . In the lower right part of figure, the mean values are compared, and the G, R, RE and NIR bands of the Parrot Sequoia

structures influence. This step type pattern between the visible regions of the electromagnetic spectrum and $N I R$ is characteristic of green vegetation. Beyond the $N I R$, the short wave infrared region (1300 $\mathrm{nm}$ and above), an absorption peak at 1,450 $\mathrm{nm}$ can be perceived as a result of the presence of water. On the contrary, in the contaminated leaves there is a noticeable dispersion in the spectral curves, which is due to the fact that the contamination covers at most $50 \%$ of the leaf, and the readings of each curve are made randomly along the leaf between contaminated areas and not contaminated. The main difference between healthy and contaminated leaves is seen, for orange rust, in a decrease of $\rho(\lambda)$ for the region between 750 and $900 \mathrm{~nm}(R E \sim N I R)$, and for brown rust in an increase of $\rho(\lambda)$ in the region between 600 and $700 \mathrm{~nm}(R)$, a decrease of $\rho(\lambda)$ in the region between 750 and $900 \mathrm{~nm}(R E \sim N / R)$, and an increase of $\rho(\lambda)$ in the region between 1,400 and $1,600 \mathrm{~nm}$. Furthermore, the difference between leaves contaminated with orange and brown rust is mainly seen in the $R, R E \sim N I R$ and between 1,400 and $1,600 \mathrm{~nm}$ regions.

Quantifying the differences in the spectral bands of the Parrot Sequoia multispectral camera, it can be 

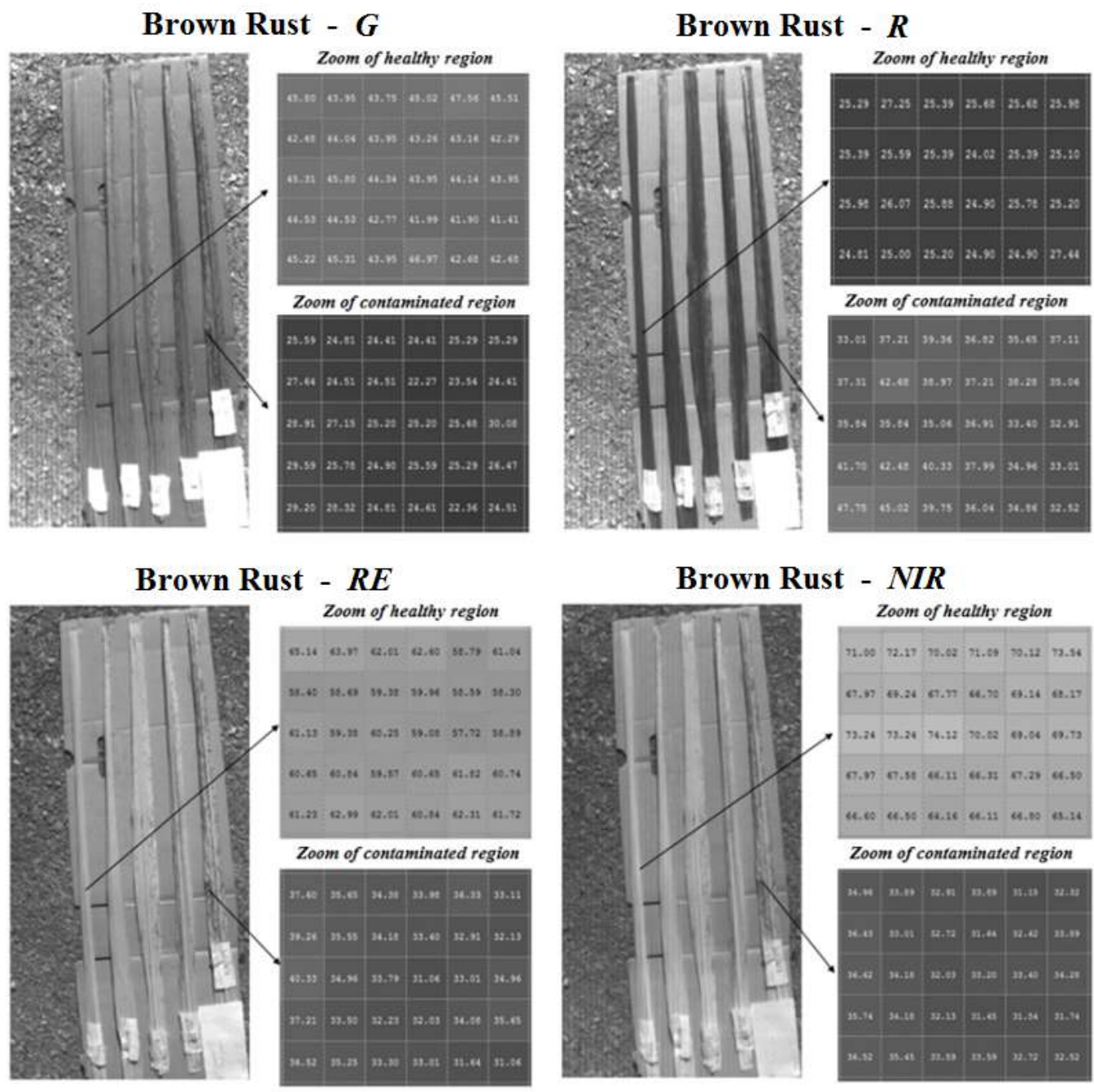

Figure 6 Images obtained by the four bands of the multispectral camera in leaves contaminated with brown rust. Reflectance values showing a point of a healthy region and a contaminated region
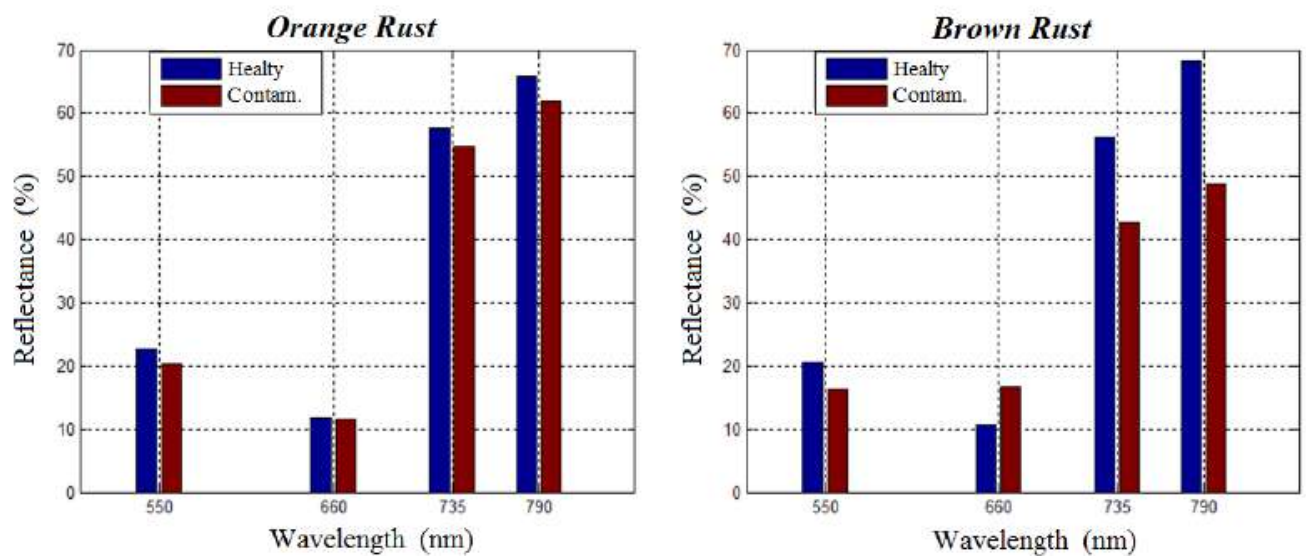

Figure 7 Comparative values of reflectance between healthy and contaminated leaves at degree 4 of $A L A$ for the two types of rust in the Parrot Sequoia camera bands 
observed that in the leaves contaminated with orange rust (top row of Figure 4), the average reflectance decreases in the $G$ band from $22.6 \%$, in the healthy leaf, to $20.01 \%$ in the contaminated leaf. In addition, the $R$ band remains almost unchanged, and both the $R E$ and NIR bands decrease from $57.67 \%$ and $65.85 \%$, to $55.35 \%$ and $63.42 \%$ respectively. On the other hand, the difference in signatures of spectral reflectance between healthy leaf and contaminated with brown rust is much greater. In the $G$ band it decreases from $20.56 \%$ reflectance in the healthy leaf to $16.3 \%$ in the contaminated leaf, while in the $R$ band an increase is produced from $10.73 \%$ up to $16.78 \%$. However, the greatest differences are seen in the RE and NIR bands, where the reflectance values decrease from $56.21 \%$ and $68.2 \%$ in the healthy leaf to $42.63 \%$ and $48.85 \%$ in the contaminated leaf. Additionally, the spectral signatures of the leaves contaminated with both types of rust also exhibit differences. It is important to emphasize that those leaves that are infected with orange rust will present a higher reflectance than the leaves infected with brown rust in the $G, R E$ and NIR bands.

These differences can be better appreciated in Figure 5 for the case of brown rust. In this figure, the mean values and standard deviations of the reflectance values for healthy leaf $(0 \% A L A)$ are plotted, as well as contaminated in grade 1, 2, 3 and 4 (up to $50 \%$ of $A L A$ ) with this type of rust. In addition, the mean values of the spectral signatures for the five grade are included in the lower right corner, indicating the wavelength values corresponding to the $G$, $R, R E$ and NIR sensors of the Parrot Sequoia multi-spectral camera. These mean values and standard deviations were obtained by taking between 17 and 24 readings on each leave. As can be seen, not only is there evidence of the notable difference that spectral signatures have between healthy and contaminated leaves, mainly from $15 \%$ of contamination (grade 2 of $A L A$ ), but also that in the four monochromatic bands that can sense the Parrot Sequoia multispectral camera most of these differences occur. This same analysis carried out for the leaves contaminated with orange rust shows less significant differences between the different grade of contamination and between these and the healthy leaves.

These results were obtained with higher spectral resolution than that previously published by [33], which used the Hyperion EO-1 satellite which has only 220 spectral bands in the range of $400 \mathrm{~nm}$ to $2,500 \mathrm{~nm}$ and a spatial resolution (GSD) of $30 \mathrm{~m}$.

\subsection{Multispectral images analysis}

The images obtained did not undergo any adjustment process. As an example, the images in the four multispectral bands obtained from the leaves contaminated with brown rust can be seen in Figure 6 without radiometric correction, as well as the reflectance levels that emit a healthy region of interest and another contaminated region. The radiometric correction can equalize the sunlight used to obtain these multispectral images with the light of the halogen lamp used to obtain the spectral reflectance curves.

In spite of the numerical differences due to the uneven illumination, and the non-radiometric correction, the proportionality that exists between them and the reflectance characteristic of the spectral reflectance signatures can be verified. For healthy regions: low reflectance in the $R$ band, with high reflectance in the $R E$ and NIR bands. For the regions contaminated with both types of rust: decrease of the spectral reflectance in the $G$, $R E$ and NIR bands, with an increase of reflectance in the $R$ band. This increase in the $R$ band is more appreciable for the leaves contaminated with brown rust. Figure 7 shows these values comparatively in the four bands of the Parrot Sequoia camera for the cases of healthy and contaminated leaves in grade 4 of ALA with orange and brown rusts. This figure confirms the result obtained previously by spectrometry, in which differences in reflectance between healthy and contaminated leaves are significant for brown rust, but not for orange rust.

\subsection{Vegetation index}

The NDVI calculated from the reflectance values measured by spectrometry shows clear differentiation between healthy and contaminated zones, mainly for brown rust, been greater the index value in healthy areas than in contaminated areas. From Figure 7, the minimum difference between NDVI values in healthy and contaminated areas for the leaves with orange rust is 0.1327 , while for the leaves with brown rust is 0.2398 . Using the reflectance values obtained by the multispectral images (Figure 6), the NDVI was calculated to obtain the images shown in Figure 8 for both types of rust. In this figure, the numerical values of the NDVI are shown in a pixel of a healthy area and in another of a contaminated area, the numerical difference between these zones being corroborated for both types of rust. In this case, an average difference between points of the uncontaminated leaf and contaminated points of 0.2081 for orange rust and 0.2379 for brown rust is obtained. Taking into account that the NDVI varies between -1 and 1, this represents a ratio of relative decrease of the index between contaminated areas with respect to non-contaminated areas in approximately the $11.9 \%$ for brown rust and $9.9 \%$ for orange rust.

Unlike what was published in [33], where the $R$ and $N I R$ bands are combined with the short wave infrared (SWIR) at 1,600 $\mathrm{nm}$ from the Hyperion EO-1 satellite to 
NDVI Orange Rust

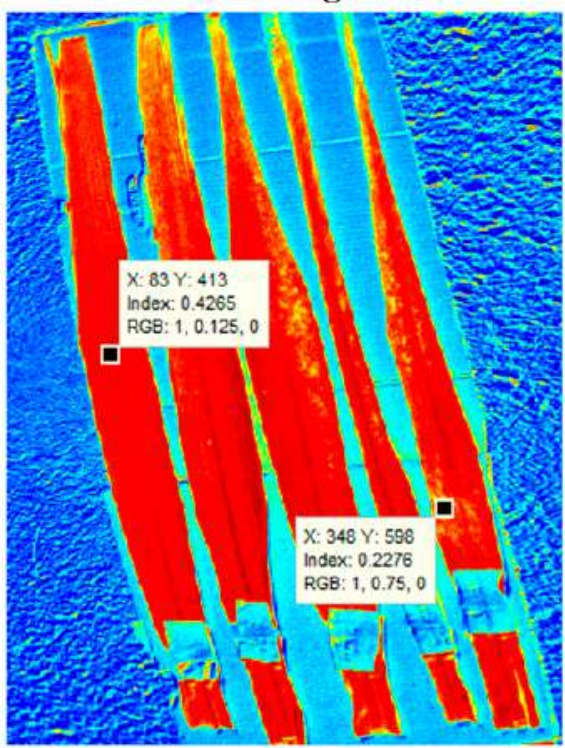

NDV Brown Rust

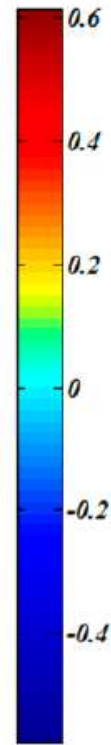

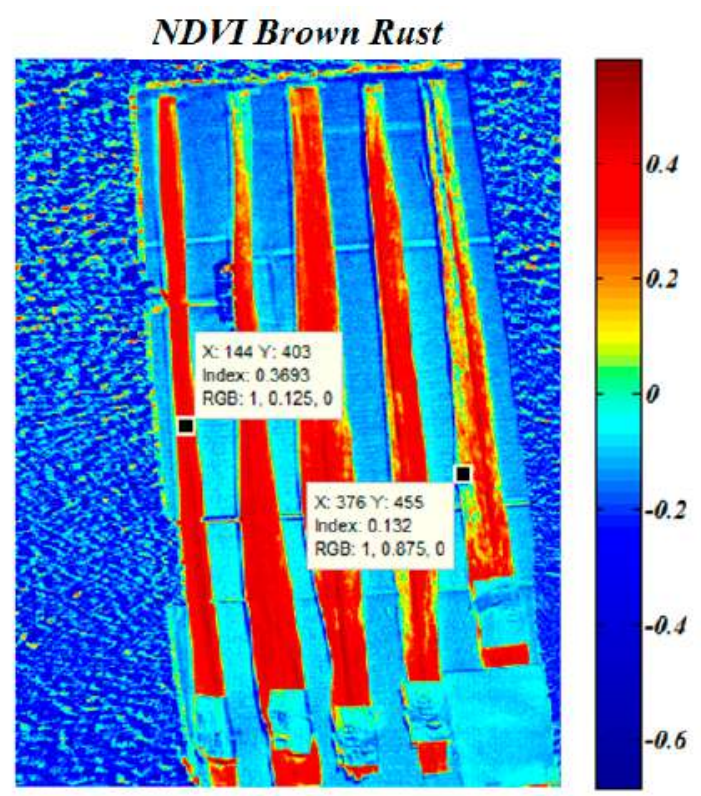

Figure 8 NDVI calculated from the multispectral images for each type of rust indicating the numerical value of the index in one pixel of a healthy region and in another of a contaminated region for each type of rust

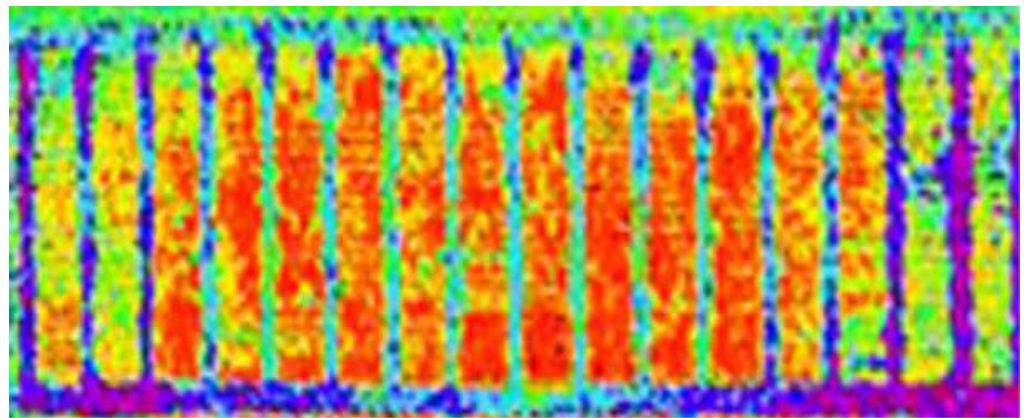

Figure 9 Example of NDVI calculated on parcels of sugarcane susceptible to rust

achieve a high differentiation between sugar cane plants contaminated with orange rust, this work demonstrates the possibility of not using the SWIR band. This makes it possible to use small multispectral cameras, which have only the spectral bands $R$ and NIR, placed on board vehicles flying at low altitude, to monitor with high spatial resolution parcels susceptible to brown rust and orange rust.

The second validation, carried out at field level, flying over sugar cane parcels susceptible to each type of rust, also confirms the validity of the NDVI obtained by multispectral imaging to differentiate areas contaminated with rust from healthy areas. Figure 9 shows an example of an image with the NDVI obtained. The validation of the aerial images was carried out by an expert from the ETICA Centro Villa Clara, where the experiments were carried out.

\section{Conclusions}

The spectral reflectance signature of the plants is very useful in precision agriculture due to its typical vegetation characteristic. The spectral reflectance signatures obtained for sugar cane leaves (Saccharum spp.) contaminated with brown rust (Puccinia melanocephala) and orange rust (Puccinia kuehnii) were obtained with spatial and spectral resolutions that exceed those previously reported in the literature. The difference in reflectance between healthy and contaminated leaves in the $R$ and NIR bands of the electromagnetic spectrum makes it possible to use combinations of these bands to detect contamination with both orange and brown rust. An example of this is the NDVI calculation, either using laboratory-level spectrometry or field-level multispectral imaging using a low-cost camera. By flying at a relatively low altitude with a low-cost multispectral camera, a high spatio-temporal resolution can be achieved to detect 
orange rust and brown rust. However, the NDVI showed minor differences $(9.9 \%)$ between healthy and orange rust contaminated leaves at the laboratory level. This is not the case for leaves contaminated with brown rust, in which the NDVI obtains significant differences (11.9\%) between healthy and contaminated leaves from ALA grade 2 . Therefore, the results provided by other vegetation indices should be analyzed, differentiating healthy and diseased regions with orange rust. In order to distinguish between healthy and rust-contaminated regions in a sugarcane leaf, the height of the flight must be such that the GSD is comparable to the area of the spots due to contamination in the leaves.

\section{Competing interest}

None declared under financial, profesional and personal competing interests

\section{Acknowledgment}

This work has been possible thanks to the valuable collaboration provided by the Estación Territorial de Investigaciones de la Caña de Azúcar (ETICA Centro Villa Claral in Villa Clara, who facilitated sugarcane samples and specialized advice, as well as the Laboratory of Spectrometry in the Faculty of Agricultural Sciences at Universidad Central "Marta Abreu" de Las Villas, who allowed to obtain the spectral reflectance signatures.

\section{References}

[1] R. Park and C. Wellings, "Somatic hybridization in the uredinales," Annual Review of Phytopathology, vol. 50, september 2012. [Online]. Available: https://doi.org/10.1146/annurev-phyto-072910-095405

[2] M. Saba and A. Khalid, "Species diversity of genus Puccinia (Basidiomycota, Uredinales) parasitizing poaceous hosts in Pakistan," International Journal of Agriculture and Biology, vol. 15, no. 3, pp. 580-584, Jan. 2013.

[3] J. Hoy and C. Hollier, "Effect of brown rust on yield of sugarcane in Louisiana," Plant Disease, vol. 93, no. 11, November 2009. [Online]. Available: https://doi.org/10.1094/PDIS-93-11-1171

[4] K. Muhammad, S. Afghan, Y. Ban, and J. Iqbal, "Genetic variability among the brown rust resistant and susceptible genotypes of sugarcane by rapd technique," Pakistan Journal of Botany, vol. 45, no. 1, pp. 163-168, Feb. 2013.

[5] R. Peixoto and et al, "Development and characterization of microsatellite markers for Puccinia melanocephala, causal agent of sugarcane brown rust," Proc. Int. Soc. Sugar Cane Technol., vol. 28, pp. 244-247, 2013.

[6] R. Peixoto and et al, "Genetic diversity among Puccinia melanocephala isolate from Brazil assessed using simple sequence repeat markers," Genetics and molecular research: GMR, vol. 13, no. 3, september 26 2014. [Online]. Available: https://doi.org/10.4238/2014.September.26.23

[7] J. Comstock and et al, "Presence of BRU1 brown rust resistance in the CP sugarcane development programs," presented at XI Pathology and IX Entomology Workshops Program, Guayaquil, Ec., 2015.
[8] L. Pérez and et al, "Definitive identification of orange rust of sugarcane caused by Puccinia kuehnii in Cuba," Plant Pathology, vol. 59, no. 4, june 2010. [Online]. Available: https://doi.org/10.1111/ j.1365-3059.2009.02248.x

[9] M. Cadavid, J. Ángel, , and J. Victoria, "First report of orange rust ofsugarcane caused by Puccinia kuehnii in Colombia," Plant Disease, vol. 96, no. 1, january 2012. [Online]. Available: https: //doi.org/10.1094/PDIS-05-11-0406

[10] G. Briggs and et al, "First report of orange rust sisease of sugarcane in the Dominican Republic," Plant Disease, vol. 98, no. 7, july 2014. [Online]. Available: https://doi.org/10.1094/PDIS-01-14-0044-PDN

[11] J. Comstock and et al, "La roya naranja de la caña de azúcar, una enfermedad emergente: su impacto y comparación con la roya marrón," Ciencia y Tecnología de los Cultivos industriales, vol. 5, no. 7, pp. 12-21, 2015.

[12] C. Funes and et al, "First report of orange rust of sugarcane caused by Puccinia kuehnii in Argentina," Plant Disease, vol. 100, no. 4, november 2015. [Online]. Available: https://doi.org/10.1094/ PDIS-09-15-1099-PDN

[13] D. Zhao, N. Glynn, B. Glaz, J. Comstockn, and S. Sood, “Orange rust effects on leaf photosynthesis and related characters of sugarcane," Plant Disease, vol. 95, no. 6, june 2011. [Online]. Available: https://doi.org/10.1094/PDIS-10-10-0762

[14] R. Raid and S. Sullivan, "Common rust," in A guide to sugarcane diseases, P. Rott and et al, Eds. CIRAD and ISSCT, 2000, pp. 85-89.

[15] B. Croft, R. Magarey, and P. Whittle, "Disease management," in Manual of Canegrowing, M. Hogarth and P. Allsopp, Eds. Bureau of Sugar Experiment Stations, 2000, pp. 263--289.

[16] CENICAÑA. (2014, feb. 19) Enfermedades de la caña de azúcar en Colombia. [Online]. Available: https://www.cenicana. org/enfermedades-de-la-cana-de-azucar-en-colombia/

[17] O. Aday and et al, "Caracterización de los síntomas de la roya naranja (Puccinia kuehnii (W. Krüger) E. J. Butler) en cuatro cultivares de caña de azúcar en Cuba," Centro Agrícola, vol. 49, no. 2, pp. 61-67, Apr. 2017.

[18] A. Koschan and M. Abidi, Digital Color Image Processing. New Yersey, EE.UU.: John Wiley \& Sons, 2007.

[19] M. Peres, Focal Encyclopedia of Photography: Digital Imaging, Theory and Applications, History, and Science, 4th ed. Elsevier Focal Press, 2007.

[20] G. saw and H. Bruke, "Spectral imaging for remote sensing," Lincoln Laboratory Journal, vol. 14, no. 1, pp. 3-28, 2003.

[21] Y. Fan and et $a l$, "Fast detection of striped stem-borer (chilo suppressalis walker) infested rice seedling based on visible/near-infrared hyperspectral imaging system," Sensors (Basel), vol. 17, no. 11, october 27 2017. [Online]. Available: http://doi.org/10.3390/s17112470

[22] J. Müllerová and et al, "Timing is important: Unmanned aircraft vs. satellite imagery in plant invasion monitoring," Front Plant Sci, vol. 8, may 31 2017. [Online]. Available: http://doi.org/10.3389/fpls. 2017.00887

[23] S. Thomas and et al, "Benefits of hyperspectral imaging for plant disease detection and plant protection: a technical perspective," Journal of Plant Diseases and Protection -New Series-, vol. 125, no. 3, september 2017. [Online]. Available: http://doi.org/10.1007/ s41348-017-0124-6

[24] S. Aggarwal, "Principle of remote sensing," in Satellite Remote Sensing and GIS Applications in Agricultural Meteorology,, Dehra Dun, India, 2005, pp. 23-38.

[25] R. Kokaly, D. Despain, R. Clark, and K. Livo, "Spectral analysis of absorption features for mapping vegetation cover and microbial communities in yellowstone national park using aviris data," in Integrated Geoscience Studies in the Greater Yellowstone Area-Volcanic, Tectonic, and Hydrothermal Processes in the Yellowstone Geoecosystem, L. Morgan, Ed. U.S. Geological Survey Professional Paper 1717, 2007, pp. 463-489.

[26] S. Sankaran and et al, "Low-altitude, high-resolution aerial imaging systems for row and field crop phenotyping: A review," European Journal of Agronomy, vol. 70, october 2015. [Online]. Available: https://doi.org/10.1016/j.eja.2015.07.004 
[27] J. Gago and et al, "Uavs challenge to assess water stress for sustainable agriculture," Agricultural Water Management, vol. 153, may 1 2015. [Online]. Available: https://doi.org/10.1016/j.agwat. 2015.01 .020

[28] J. Zhou and et al, "Aerial multispectral imaging for crop hail damage assessment in potato," Computers and Electronics in Agriculture, vol. 127, september 2016. [Online]. Available: https: //doi.org/10.1016/j.compag.2016.06.019

[29] J. Díaz, “Estudio de Índices de vegetación a partir de imágenes aéreas tomadas desde UAS/RPAS y aplicaciones de estos a la agricultura de precisión," M.S. thesis, Universidad Complutense de Madrid, Madrid, España, 2015.

[30] R. Sanderson, "Introduction to remote sensing," presented at Anais do XVI Simpósio Brasileiro de Sensoriamento Remoto, Brasil, 2013.

[31] E. Abdel, F. Ahmed, M. Berg, and M. Way, "Potential of spectroscopic data sets for sugarcane thrips (Fulmekiola serrata Kobus) damage detection," International Journal of Remote Sensing, vol. 31, no. 15, september 2010. [Online]. Available: https://doi.org/10.1080/01431160903241981

[32] E. Akemi and N. Nobuhiro and A. Garcia, "Análise do comportamento espectral de amostras de cana-de-açúcar infectadas com ferrugem alaranjada," in Anais XVI Simpósio Brasileiro de Sensoriamento Remoto - SBSR, Foz do Iguaçu, Brazil, 2013, pp. 0258-0265.

[33] A. Apan, A. Held, S. Phinn, and J. Markley, "Detecting sugarcane 'Orange Rust' disease using E0-1 hyperion hyperspectral imagery," International Journal of Remote Sensing, vol. 25, no. 2, 2004. [Online]. Available: https://doi.org/10.1080/01431160310001618031

[34] R. Islam and M. Rafiqul, "An image processing technique to calculate percentage of disease affected pixels of paddy leaf," International Journal of Computer Applications, vol. 123, no. 12, august 2015. [Online]. Available: https://doi.org/10.5120/ijca2015905495

[35] E. Virtudazo, H. Nojima, and M. Kakishima, "Taxonomy of Puccinia species causing rust diseases on sugarcane," Mycoscience, vol. 42 no. 2, april 2001. [Online]. Available: https://doi.org/10.1007/ BF02464133

[36] C. Li, K. Sivasithamparam, and M. Barbetti, "Complete resistance to leaf and staghead disease in Australian Brassica juncea germplasm exposed to infection by Albugo candida (white rust)," Australasian Plant Pathology, vol. 38, no. 1, january 2009. [Online]. Available: https://doi.org/10.1071/AP08078

[37] K. Neumenn, "Digital aereal cameras," unpublished.
[38] A. Kavvadias, E. Psomiadis, M. Chanioti, E. Gala, and S. Michas, "Precision agriculture - comparison and evaluation of innovative very high resolution (UAV) and landsat data," presented at International Conference on Information and Communication Technologies in Agriculture Food and Environment-HAICTA, Kavala, GR, 2015.

[39] J. Beltran, "Method development to process hyper-temporal remote sensing ( $r s$ ) images for change mapping," M.S. thesis, International Institute for Geo-information Science and Earth Observation- ITC, Enschede, Netherlands, 2007.

[40] M. Rahman, A. Islam, and M. Rahman, "NDVI derived sugarcane area identification and crop condition assessment," Plan Plus, vol. 1, pp. 1-12, Jan. 2004

[41] N. Virlet, E. Costes, S. Martinez, J. Kelner, and J. Regnard, "Multispectral airborne imagery in the field reveals genetic determinisms of morphological and transpiration traits of an apple tree hybrid population in response to water deficit," Journal of Experimental Botany, vol. 66, no. 18, september 2015. [Online]. Available: https://doi.org/10.1093/jxb/erv355

[42] D. Zhao, V. Gordona, J. Comstocka, N. Glynnb, and R. Johnsonc, "Assessment of sugarcane yield potential across large numbers of genotypes using canopy reflectance measurements," Crop Science, vol. 56, no. 4, july 2016. [Online]. Available: https: //doi.org/10.2135/cropsci2015.12.0747

[43] K. Johansen and et al, "Using GeoEye-1 imagery for multi-temporal object-based detection of canegrub damage in sugarcane fields in Queensland, Australia," GIScience \& Remote Sensing, vol. 55, no. 2, 2018. [Online]. Available: https://doi.org/10.1080/15481603. 2017.1417691

[44] L. Kunze and et al, "Classification analysis of NDVI time series in metric spaces for sugarcane identification," presented at 20th International Conference on Enterprise Information Systems, Funchal-Madeira, PT, 2018.

[45] I. Pinheiro and et al, "Prediction of sugarcane yield based on NDVI and concentration of leaf-tissue nutrients in fields managed with straw remova," Agronomy, vol. 8, no. 9, september 2018. [Online]. Available: https://doi.org/10.3390/agronomy8090196

[46] Q. Zheng and et al, "New spectral index for detecting wheat yellow rust using Sentinel-2 multispectral imagery," Sensors, vol. 18, no. 3, march 15 2018. [Online]. Available: https://doi.org/10.3390/ s18030868 